\title{
Psychological and pedagogical support of children with disabilities in the system of additional education
}

\author{
E.A. Ekzhanova ${ }^{1 *}$ and I.L. Solovyeva ${ }^{2}$ \\ ${ }^{1}$ Moscow City University, Moscow, Russia \\ ${ }^{2}$ Moscow City University, Moscow, Russia
}

\begin{abstract}
The article focuses on the problem of psychological and pedagogical support of a child with disabilities in additional education from preschool age through the period of schooling to the adulthood. In this article we discuss specific Individualized Educational Programs (IEP), using of effective pedagogical technologies in working with children of different nosological groups. The reader is referred to following technologies: "play environment", "a successful first-grader", "skillful hands", "sports, leisure, development", assessment of success in various fields of activity, dynamic observation of the individual trajectory of additional education; technologies of influence on the motivational component of the additional education program and its extrapolation to the professional credo of a teenager with disabilities. The article describes conditions and opportunities for the disclosure of creative potential of children with disabilities, the opportunities for their career growth and other aspects of their realization in society.
\end{abstract}

\section{A problem statement}

One of the most important requirements of lifelong education for a child with disabilities is an individual approach and creating a situation of success for the child at all stages of his life $[12,13]$. The system of additional education provides optimal opportunities for the implementation of these requirements in a broad paradigm of pedagogical effects. The Law on Education offers a wide range of activities and a large number of types of institutions of additional education, differing quantitatively and qualitatively. The Law lists city and district institutions, multidisciplinary institutions, long-term and temporary, creativity centers, children's parks, children's camps, art schools, groups and studios. All this diversity makes it possible to implement programs of additional education for a certain type of activity or several at the same time, carry out work on the basis of various types of educational programs, provide services to meet the educational needs and individual interests of children both with normal development and with disabilities at different ages [21].

\footnotetext{
* Corresponding author: ipcs-profped@yandex.ru
} 
It should be noted that the legislator postulated the uniqueness and originality of these institutions, since they were created and are still being created for the needs of specific consumers of services, both among children and adults. Individualized programs of additional education, copyright programs and programs of additional professional education are implemented for children with disabilities [20].

Individualized programs of additional education begin to be implemented already at the stage of preschool childhood. For children with disabilities, a special "play environment" is created in which a child with sensory, motor, cognitive impairments can realize his/her interests and abilities. It is no secret that children with disabilities have highly developed compensatory skills. For example, children with visual impairments often show musical skills, children with effects of cerebral palsy can achieve success in intellectually rich activities - chess, aircraft modeling, technical creativity. In the initial stages of mastery learning children can be supported by a teacher-defectologist or tutor who is competent in providing targeted assistance to children with disabilities [14].

Author's programs can be focused on helping children with various disabilities, taking into account their specific needs. Programs develop the intellect of children, expand their worldview, develop speech skills, prepare for literacy training, and engage in early career guidance work.

Additional vocational education for a child with disabilities is especially important when the child finishes school and the transition to the phase of vocational training. According to studies by various authors, presence of a tutor / teacher of additional education next to a child in this difficult period greatly facilitates the child's efforts and improves the quality of entering adulthood $[2,4,5,9]$.

The total number of students with disabilities and children with special needs getting additional education in all areas of general programs, according to the Ministry of Education of Russia, amounted to more than 536 thousand people in 2018. At the same time, the proportion of children with disabilities aged 5 to 18 receiving additional education exceeded $40 \%$ of the total amount of children with disabilities. The national project "The Success of Every Child" raises the bar: ensuring the availability and improving the quality of Additional Education for Children (AEC) and increasing by 2020 the share of schoolchildren enrolled in additional education programs to $70-75 \%$.

If you look at the professional standard approved by the Ministry of Labor and Social Protection on January 10, 2017, then the description of labor functions included in this standard reflects three blocks of requirements: for the content of pedagogical support, for the organization of the educational environment in the system of additional education in which IEP is implemented, and to the organizational and methodological support for the implementation of IEP for a child with disabilities and special needs. Therefore, in creating of any technologies for supporting additional education programs, all three components should be presented [22].

The authors of the article see the organization of psychological and pedagogical support of a child as the leading component, on which the maximizing the creative potential of a teenager with disabilities in the system of additional education depends, including the personalization of mechanisms of his self-development and self-realization - the future life success of a child with disabilities. Understanding at the same time, by adaptation in the system of additional education, the growing competence of a teenager in the field of determining the existing conditions and applying the formed creative methods of creativity, which will lead him to effective inclusion in his chosen professional activity.

What is the place of a tutor in this complex and responsible area? This is the implementation of mentoring with position of pedagogical optimism and faith in the adolescent's adequate social resources, on the one hand, and building shortcuts that in order to smooth the possible risks of including the construct of creative expression, which opens 
the way for a boy / girl with disabilities to himself, to his interests, opportunities and potentials, supporting the child along the entire trajectory of additional education and teaching him accessible ways of self-acceptance and self-presentation.

We consider the technology of tutoring a child with disabilities based on the creation of an individual educational program (IEP) in the system of additional education. In the special literature there is the following definition: "this is a personal way of realizing the personal potential of each student in education" [1].

When developing an IEP, it is important for specialists to take into account the following indicators:

-the actual age of a teenager with disabilities;

- his mental or physical development needs;

-potential inclinations and preferences;

-correspondence of the parameters of mental and physical development, the state of the physical health to the requirements of the program of creative activity;

-the presence of creative preferences in his family;

-the presence in additional education of the traditions of school competitions and shows;

-providing network interaction between the school system of additional education and city, regional, nationwide exhibitions and festivals;

- staffing of the system of additional education [17].

\subsection{The objective of the work}

The activity of a tutor / teacher in the system of additional education includes the following components: educational data, which contains information about the direction of the additional education program, the necessary competencies for its development, physical health indicators; provides educational diagnostics, carries out a diagnostic test, creative selection, inclusion in festival activities.

A teenager, as a spectator with the tutor and parents, participates in such events as, for example, the All-Russian competition "Colors of All Russia", the international festival "the Silk Road": inclusive creativity, the All-Russian festival "Flap of the wing", etc [13,14, 15, 16].

For some of teenagers we have developed creative tests. Clownery:

General educational information. The work of a clown on stage with separate acts (reprise); possible participation in the concert program. The clown's competence: the performer must be able to select a reprise, think over the scenography for its performance; choose a costume for the performance of a reprise; to think over the light and musical accompaniment of the concert number.

Creative test: the possibility of providing work in a theater / circus / Palace of Culture.

Creative selection. It is necessary to possess artistry, the ability to interest the audience, artistic taste, perseverance, fine sensitivity of hands $[6,8]$.

Requirements for creative professional training. He/she should know: the basis of acting, scenography, clowning, the history of circus art, composition of a reprise, various forms of its presentation, techniques and features of all interaction with the audience. Creative success is largely determined by the coincidence of the desires / preferences of the person and his potential.

Let's dwell in more detail on the main directions of the tutor's activity in the system of additional education:

- creative diagnostics (helping a teenager in self-knowledge, determining real opportunities and creative abilities necessary to achieve creative goals);

- correction of the personal development of a teenager to prepare for future creative activity; 
- psychological support for self-determined adolescents, which allows instilling confidence and optimism in relation to their creative future, making an adequate professional choice when planning life and professional prospects. There are other areas in the tutor's activities, but they, as a rule, are associated with the individualization of the approach to each student [7].

\section{Materials and the results of the research}

The implementation of psychological and pedagogical support of students with disabilities in the process of lifelong education allows the personalization of the socialization process of each of the children, including the system of additional education, and in work with the family and the child at his place [4].

The inclusion of a child with disabilities into network interaction through creative festivals can contribute to the development of a special personal potential, the ability to build their own images of surrounding objects, phenomena and design in a student with disabilities a fertile ground for creative self-development, launching a successful mechanism of social inclusion. In this case, the phenomenon of psychological and pedagogical support of the process of including children in inclusive creativity through participation in creative studios, competitions, festivals can be positioned as a kind of classification and evaluation template that ensures the optimization of the picture of the world, its artistic components, under the guidance of a teacher / tutor of additional education.

In this case, festivals and arts competitions appear as a phenomenon of a resource of quality and accessibility, filling children with special needs with a whole paradigm. It helps with skillful pedagogical guidance to open prerequisites for the formation of trajectories of successful social adaptation of a person with disabilities and improvement of the quality of his life, on the one hand, and on the other hand, by the recognition procedure: victory in a competition, the title of laureate are in demand when entering art professional colleges $[14,15,19,20]$.

The most effective educational technology for growing of motivational component when choosing a profession by a teenager with disabilities is the technology "Personalization of the process of social inclusion by means of additional education", which allows the child, with the help of a tutor, to determine the conditions and ways of realizing creative growth. Its integral parts are:

Study and formation of personal, creative preferences in the system of additional education;

Further study of the student, creative tests, individual design in the system of additional education, taking into account the personal capabilities of each teenager, his interaction with various social institutions working for each of the children: family, general education organization, palace of creativity, studio at the place of residence.

\section{Conclusions}

Ensuring the quality and accessibility of the system of additional education for a student with special needs involves a network of socio-cultural activities, consisting of psychological and pedagogical support of creative activities both in educational institutions, as well as in children's palaces of creativity, as well as through participation in urban, regional, interregional and other events, including festivals of children's creativity at various levels. As part of the network interaction of such festivals, the resources of additional education can be used to reveal the personal creative potential of each student 
with special needs, become the foundation for their personal self-development, creative and professional self-determination.

\section{References}

1. S.V. Alekhina, Autism and developmental disorders, 1, 1-6 (2013)

2. B.V. Belyavsky, I.L. Solovieva, Special Education, 2 (42), 5-14 (2016)

3. E.A. Ekzhanova, The basics of integrated learning: a manual for universities (M., Drofa, 2008)

4. E.A. Ekzhanova , E.V. Reznikova, Special Education, 4 (52), 21-41 (2018)

5. N.N. Zybareva, Tutoring support for inclusive education (http://www.thetutor.ru/lechebn_ped/articles.htm (date accessed 15.10.2018)

6. E.A. Klimov, How to choose a profession. Book for students (M., 1990)

7. T.M. Kovaleva, Not a teacher, not a psychologist, not a class teacher: Tutoring as one of the ways to overcome formal pedagogy, First of September, 66 (2004)

8. G.V. Rezapkina, Profession and career, School psychologist, 2 (2009)

9. I.L. Solovyova, Individual trajectories of higher professional education for persons with hearing disabilities, 147-155 (Inclusive professional education of persons with disabilities: Sat. materials of an interdisciplinary conference (Moscow, FIRO, May 2009)

10. I.L. Solovieva, Socialization of students with hearing disabilities by means of extracurricular activities in the system of continuing education (M., "New Education", 2017)

11. I.L. Solovieva, Supportive education for young people with disabilities and special needs. Competence of a support specialist, Secondary vocational education, 7, 5-10 (2020)

12. 12 N.V. Bondarenko, Formation of lifelong education in Russia: analysis based on the results of all-Russian polls of the country's adult population (Moscow: National Research University Higher School of Economics, 2017)

13. 13 M.K. Gorshkov, G.A. Klyucharev, Continuing education in the context of modernization (M., IS RAN, FGNU TsSI, 2011)

14. 14 I.N. Zarubina, I.L. Solovieva, Development of guidelines for accompanying persons with sensory impairments (deaf, hard of hearing, blind and visually impaired) in institutions of secondary and higher vocational education (State registration number in Centre of Information Technologies and Systems of Executive State Authorities: 1201364964, 2013-2015)

15. I.L. Solovieva, State certification in special schools: methodological recommendations, Educational policy, 3 (69), 90-93 (2015)

16. I.V. Evtushenko, A.P. Simonov, I.L. Solovyeva, L.R. Khuzina, K.A. Armeninova, R.Z. Zakirov, A.I. Evtushenko, G.Y. Eroshina, T.L. Lyubimova, S.A. Osokina, Modern high technologies. 7, 157-163 (2019)

17. I.N. Popova, I.L. Solovieva, Education and training of children with developmental disabilities, 2, 42-48 (2020)

18. I.N. Popova, I.L. Solovyeva, Improving the software and methodological support and content of activities in the field of additional and non-formal education in the process 
of implementing models of social inclusion, (M., Delo Publishing House, Russian Academy of National Economy and Public Service, 2019)

19. I.L. Solovieva, Festivals of inclusive creativity as a socio-cultural phenomenon of self-realization of persons with disabilities in the system of lifelong education, 91-97 (Continuous inclusive education: theory, history, methodology: materials of the XI International theoretical and methodological seminar (March 25, 2019)

20. E.A. Medvedeva, Z.I. Zhuravleva, A.S. Pavlova, Inclusive art and developmental space of additional education as a way of socialization of the personality of children with disabilities, (Moscow: MGPU, 2018)

21. "Education Act in the Russian Federation", (N 273-FZ, December 29, 2012)

22. Order of the Ministry of Labor of the Russian Federation "On the approval of the professional standard "specialist in the field of education", (N 10H, October 01, 2017) 